\title{
Renal Replacement Therapy for Acute Kidney Injury in COVID-19 Patients in Latin America
}

\author{
Rolando Claure-Del Granado ${ }^{a}$ Gustavo Casas-Aparicio ${ }^{b}$ \\ Guillermo Rosa-Diez ${ }^{c} \quad$ Lilia Rizo-Topete $^{d}$ Daniela Ponce ${ }^{e}$ \\ ${ }^{a}$ Hospital Obrero No. 2 - CNS, Universidad Mayor de San Simon, School of Medicine, \\ Cochabamba, Bolivia; ${ }^{b}$ Centro de Investigación en Enfermedades Infecciosas, Instituto \\ Nacional de Enfermedades Respiratorias Ismael Cosío Villegas, Mexico City, Mexico; \\ 'Division of Nephrology, Hospital Italiano, Buenos Aires, Argentina; dUANL, Hospital \\ Univeristario "José Eleuterio González," UDEM, Hospital Christus Muguerza Alta \\ Especialidad, Monterrey, Mexico; e University of São Paulo State - UNESP, Clinical Hospital of \\ Botucatu School of Medicine, HCFMB, São Paulo, Brazil
}

\section{Keywords}

Renal replacement therapies · Latin America · Acute kidney injury · COVID-19

\section{COVID-19 and Acute Kidney Injury: The Global and Latin-American Experience}

The incidence of acute kidney injury (AKI) in hospitalized patients with COVID-19 is broad and ranges from 0.5 to $29 \%$ according to early reports from China and Italy $[1,2]$. A recent multicenter retrospective cohort in New York showed a higher incidence $37 \%$ ) and mortality (35\%). AKI was primarily seen in COVID-19 patients with respiratory failure; $89.7 \%$ of patients who were on mechanical ventilation developed AKI as compared to just $21.7 \%$ of non-ventilated patients. Furthermore, $96.8 \%$ of patients who required renal replacement therapy (RRT) were on ventilators [3]. From these first reports, AKI emerges at the same time as the acute respiratory distress syndrome, and the development of AKI is usually found in patients who progress to phase 3 of the extra-pulmonary systemic hyper-inflammation syndrome [4]. Hirsch et al. [3] reported that up to $37.3 \%$ of AKI cases occurred within the first $24 \mathrm{~h}$ of hospital admission, and AKI frequently coincides with the development of the hyperinflammation phase $[1,3]$.

Understanding COVID-19-associated AKI epidemiology and knowledge of the resources and infrastructure available for its treatment, especially for those patients who will require RRT, is essential to devise an adequate strategy for improving the care of patients with AKI. 
To date, there are no published data on the situation in Latin America, although anecdotal evidence suggests that the clinical presentation is similar. Preliminary and unpublished data from the National Institute of Respiratory Diseases (INER) in Mexico City (which is a national referral center for infectious diseases, and as a consequence, the entire hospital was transformed into a referral center for the treatment of SARS-CoV-2-infected patients) showed that the development of AKI occurs early (usually during the first $72 \mathrm{~h}$ after admission) in up to $75 \%$ of their patients, with AKI being more common among patients between $50-55$ years and in patients with obesity and hypertension. The higher incidence of AKI contrasts with what was reported in other series [1-3]. The number of nephrology consultations due to AKI in COVID-19 patients has increased across centers in Latin America; for example, at INER in Mexico City, the number of nephrology consultations has increased four-fold with 28 consultations being provided and 6-8 RRT treatments performed each day. These numbers are higher if we compare the workload the Division of Nephrology of INER usually has during influenza season, where 15-20 nephrology consultations and 3-4 RRT treatments are performed per day.

\section{Renal Replacement Therapy for Acute Kidney Injury in Latin America}

There are few reports in the literature that describe the type of RRT used for AKI in Latin America. With this goal in mind, the AKI Committee of the Latin America Society of Nephrology and Hypertension performed a survey in 2014, which for the first time provided information on the infrastructure, human resources, and equipment available for RRT in AKI patients in the region [5]. Although 246 units from 14 countries responded to the survey, the vast majority (220 units) came from only five countries, namely Argentina, Brazil, Uruguay, Chile, and Peru. This heterogeneous response was likely related to many aspects, including population size, socioeconomic development, health system organization, and the presence of an active national nephrology society. The authors found that the majority of patients were treated in units managed by the nephrology divisions of teaching hospitals. Economic support was mostly provided by public health systems. Intermittent hemodialysis (IHD) was universally performed by all of the units, whereas $40 \%$ performed prolonged intermittent renal replacement therapies (PIRRT) and only $23 \%$ provided continuous renal replacement therapies (CRRT). These last two techniques were mainly available in larger units [5].

More recently, the EPILAT-IRA Study, an observational study performed to understand the epidemiology of AKI in Latin America, showed that the most common type of RRT performed was IHD (68\%), followed by PIRRT (22\%), CRRT (10\%), slow continuous ultrafiltration (8\%), and peritoneal dialysis (PD; 5\%). Several patients received more than one type of RRT. Reasons for initiation of RRT were electrolyte and/or acid base disturbances (70\%), fluid overload (54\%), and solute control (48\%) [6].

\section{COVID-19 Patients with Dialysis Requiring AKI}

The indications for RRT for AKI remain the same regardless of the COVID-19 status of any given patient. The following special considerations should be taken into account when dialyzing patients with COVID-19:

Patients should be co-localized on a floor or intensive care unit, when possible. Co-localization within adjacent rooms can enable one dialysis nurse to simultaneously deliver dialysis to more than one patient.

\section{Karger'}


Table 1. Comparison of all available RRT techniques in Latin America for dialysis requiring COVID-19 patients with AKI

\begin{tabular}{|c|c|c|}
\hline & Advantages & Disadvantages \\
\hline CRRT & $\begin{array}{l}\text { - Therapy of choice in hemodynamically unstable patients } \\
\text { - Fewer hypotensive episodes } \\
\text { - Possible earlier renal recovery } \\
\text { - More effective management of marked fluid overload } \\
\text { - Preferred in catabolic patients or patients with high protein } \\
\text { requirements } \\
\text { - Capacity to offer different modalities (SCUF, HDFVVC, HVHF) and } \\
\text { different membranes and combination with sorbents }\end{array}$ & $\begin{array}{l}\text { - Advanced technology requiring specially } \\
\text { trained health care personnel } \\
\text { - Not available in all centers in Latin America } \\
\text { - More expensive }\end{array}$ \\
\hline PIRRT & $\begin{array}{l}\text { - When CRRT is not available, it may be preferable in } \\
\text { hemodynamically unstable patients } \\
\text { - Same technology than IHD } \\
\text { - Available in most centers across Latin America }\end{array}$ & - Difficulty to adjust the dose of antibiotics \\
\hline IHD & $\begin{array}{l}\text { - Faster correction of biochemical abnormalities (acidosis, } \\
\text { hyperkalemia, uremia, etc.) } \\
\text { - Most common technology available } \\
\text { - Available in all centers across Latin America }\end{array}$ & $\begin{array}{l}\text { - Frequent hypotensive episodes } \\
\text { - May delay renal recovery }\end{array}$ \\
\hline PD & $\begin{array}{l}\text { - Less expensive } \\
\text { - Lower risk of hypotension } \\
\text { - Requires relatively less equipment, infrastructure, and resources } \\
\text { - Available in most of the centers across Latin America } \\
\text { - Automated PD, if available, permits faster and less labor-intensive } \\
\text { correction of fluid overload }\end{array}$ & $\begin{array}{l}\text { - Increased contact between health care } \\
\text { personnel and patients when frequent } \\
\text { manual exchanges required } \\
\text { - Can increase intra-abdominal pressure, } \\
\text { interfere with respiratory mechanics } \\
\text { - Use in a prone-positioned mechanically } \\
\text { ventilated patient may be challenging }\end{array}$ \\
\hline Adsorbents & - Cytokine removal & $\begin{array}{l}\text { - Expensive } \\
\text { - Not available in all countries }\end{array}$ \\
\hline
\end{tabular}

Patients who are not critically ill but who have AKI requiring RRT should be dialyzed in their isolation room rather than being transported to the inpatient dialysis unit.

CRRT remains preferred among critically ill patients with AKI and COVID-19. Even among patients who are hemodynamically stable and could tolerate IHD, CRRT or PIRRT should be performed instead, depending upon machine and staffing availability. This is because CRRT or PIRRT can be managed without 1:1 hemodialysis nursing support. This would potentially help minimize wastage of personal protective equipment and limit exposure among hemodialysis nurses. When available hemodialysis or CRRT machines are in short supply, clinicians may need to consider treatment of AKI with PD. A comparison of the different types of RRT available in Latin America is shown in Table 1.

\section{The Use of CRRT in Latin America during COVID-19 Pandemic}

The usual RRT methods for treating COVID-19 patients with severe AKI in the Latin America region are CRRT or IHD. Both methods have advantages and disadvantages. For example, CRRT allows hemodynamic stability and great fluid removal but is expensive and time-consuming. On the other hand, IHD is cheaper and faster but induces hypotension in $20-30 \%$ of these patients [7]. The selection of the RRT modality should be based on local experience and expertise in combination with the needs of the individual patient. There are no data to support the use of convective therapies to eliminate pro-inflammatory cytokines; we must remember that convection does not differentiate pro-inflammatory cytokines from 


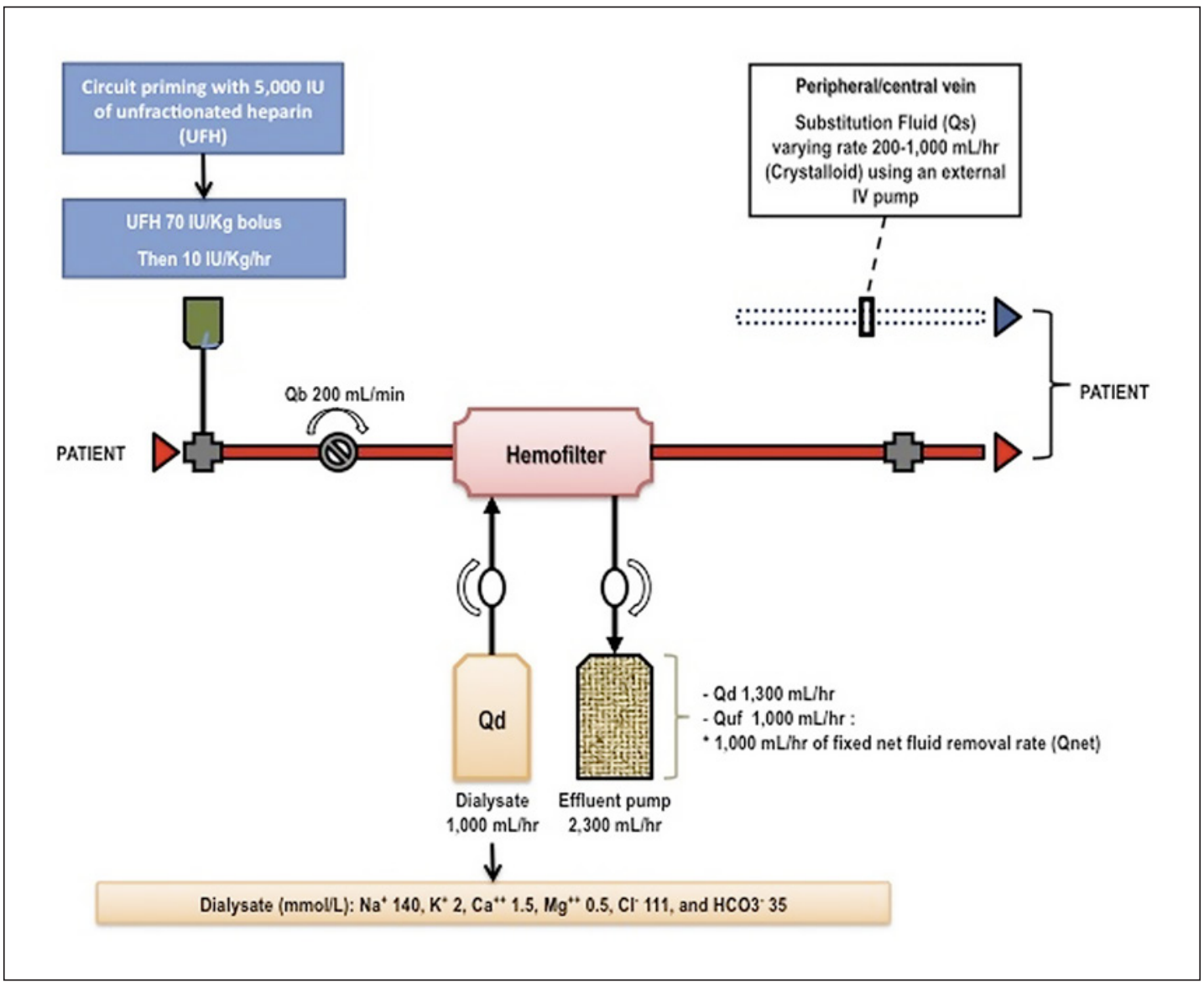

Fig. 1. Continuous venous-venous hemodialysis (CVVHD) circuit set-up at Hospital Obrero No. 2 - CNS in Cochabamba, Bolivia and the use of a fixed ultrafiltration (UF) strategy. In the fixed UF strategy, UF rate is "fixed," and the net UF rate is modified by using a substitution fluid infusion of crystalloids with a varying rate of 200-1,000 mL/h through a peripheral or a central vein. For anticoagulation, the circuit is primed with $5,000 \mathrm{IU}$ of heparin, then a second bolus of $70 \mathrm{IU} / \mathrm{kg}$ is administered, and then an infusion is started at $10 \mathrm{IU} /$ $\mathrm{kg} / \mathrm{h}$; aPTT should be monitored and the target should be 1-4 times normal ( $>40 \mathrm{~s}$ ). Measurement of aPTT should be done at $2 \mathrm{~h}$, then each $4 \mathrm{~h}$ until target is reached, then each $8 \mathrm{~h}$ during CRRT.

anti-inflammatory cytokines. We believe that convection could be used if that is their normal practice; otherwise, RRT employing predominantly diffusion should be sufficient.

In Latin America, the three most prescribed CRRT modalities are: pre-dilution CVVHDF, pre-dilution CVVH, and CVVHD with a prescribed dose $>25 \mathrm{~mL} / \mathrm{kg} / \mathrm{h}$ in order to obtain a delivered dose $\geq 25 \mathrm{~mL} / \mathrm{kg} / \mathrm{h}$. Nevertheless, practices vary at each center; for example, at Hospital Obrero No. 2 - CNS in Bolivia, we prefer the use of a diffusive type of CRRT like CVVHD in order to reduce the filtration fraction and to prescribe $\geq 30 \mathrm{~mL} / \mathrm{kg} / \mathrm{h}$ of effluent that provides a $25 \%$ margin of safety to reduce the prescribed/delivered dose ratio $[8,9]$. We have observed increased filter and circuit clotting despite using appropriate doses of regional citrate anticoagulation, with a reported filter half-life of $26 \mathrm{~h}$. However, most of the centers in Latin America where CRRT is being prescribed use heparin; higher doses of heparin are usually employed in order to keep the circuit running. In Figure 1 we show the strategy used to improve anticoagulation and the use of the fixed ultrafiltration strategy for optimizing fluid removal [10]. 
Table 2. Differences between PIRRT and CRRT

\begin{tabular}{ll}
\hline PIRRT & CRRT \\
\hline Higher fluid shifts, increased risk of hypotension & Hemodynamic stability, reduced risk for cerebral edema \\
\hline Requires conventional equipment, simple procedure & Requires especial equipment \\
\hline Easy to perform, patient mobility, flexible timing - 12 h/day & Need for trained personnel \\
\hline Lower cost & Higher cost \\
\hline Anticoagulation with heparin if needed & $\begin{array}{l}\text { Anticoagulation not always required but if it is required } \\
\text { heparin or citrate are the most common strategies }\end{array}$ \\
\hline Higher risk of bleeding (systemic anticoagulation) & Lower risk of bleeding if regional anticoagulation is used \\
\hline Risk for hypophosphatemia & $\begin{array}{l}\text { More precise solute and volume control, adequate } \\
\text { nutritional support is possible }\end{array}$ \\
\hline $\begin{array}{l}\text { Easier to perform and allows the use of one machine for } \\
\text { multiple patients }\end{array}$ & Limited to one or two patients with the same equipment \\
\hline
\end{tabular}

Unfortunately, as a consequence of the high number of patients who have overwhelmed COVID-19 referral hospitals in the region and lack of CRRT machines, the following strategy has being used across centers like INER in Mexico and Hospital Obrero No. 2 - CNS in Bolivia: CRRT machines are being used to deliver prolonged intermittent treatments (e.g., $8 \mathrm{~h}$ rather than continuous) with higher flow rates (e.g., $\geq 40 \mathrm{~mL} / \mathrm{kg} / \mathrm{h}$ ) using high blood flows ( $\mathrm{Qb} \geq 200$ $\mathrm{mL} / \mathrm{m})$.

\section{Prolonged Intermittent Renal Replacement Therapy}

In the last 20 years, PIRRT has emerged as attractive alternative, able to provide satisfactory metabolic control with low complication rates and reduced anticoagulation requirements. PIRRT achieves dialysis dose values closer to the prescribed dose and significantly higher than in IHD [11]. It also possesses the advantages of conventional hemodialysis and slow continuous therapies and reduces their inherent limitations, such as high costs and logistics and technical complications [12], which are important considerations to be made when choosing an RRT for treating COVID-19 patients with AKI (Table 2). Despite the advantages mentioned above, PIRRT is not widely used as a first treatment modality in intensive care units across Latin America, although the technological requirements are the same as those for IHD. A survey carried out in Argentina showed that possible reasons for its limited use as a first therapeutic option are a lack of sufficient dialysis nursing staff in public health systems and the fact that it was not covered by private health insurance [13]. We believe that if knowledge of this technique is expanded, it may have an important role in Latin America during the COVID-19 pandemic. Nevertheless, there is significant heterogeneity among institutions in the prescription and technology of these therapies, so standardization of terminology and establishment of prescription guidelines is necessary for their proper use [14].

\section{Karger'}




\section{Peritoneal Dialysis}

Although PD may not be considered as the first choice of RRT in case of severe AKI in COVID-19 patients, in Latin America it has been used for both AKI as well as end-stage kidney disease for more than 70 years, with Brazil, Mexico, Colombia, and Guatemala being the countries with more accumulated experience in the use of PD for treating severe AKI. The renewed interest and the strategies currently used for providing PD in AKI in Latin America are thanks to the efforts and research conducted by a group of nephrologists from Botucatu, Brazil, which have shown that high volume PD can provide similar metabolic control, with no differences in the mortality rate (58 and $53 \%$ ) or the renal function recovery ( 28 and $26 \%$ ) as compared to daily hemodialysis $[15,16]$.

PD has many advantages in the context of the COVID-19 pandemic. It does not require significant infrastructure, which is a concern in many low/middle-income countries, it is costeffective, and there is no need for systemic anticoagulation. PD is also relatively simple and requires less equipment. Moreover, utilization of automated PD can lead to the minimization of dialysis nursing exposure for the use of RRT in these patients since the used PD bags need to be changed for fresh ones only once daily with automated PD. Minimizing contact with COVID-19-positive patients reduces not only the risk of infection but also the need for personal protection equipment, an important consideration in the context of the limitations on supply. The use of PD in COVID-19 patients requiring mechanical ventilation could be a concern; however, a Brazilian study showed that PD in ventilated patients is feasible. They demonstrated that 2-liter fill volumes caused only a slight increase in intra-abdominal pressure with the first dwell and did not interfere with patients' ventilation and oxygenation. Furthermore, after the three exchanges, all ventilatory parameters improved as a result of the removal of fluid overload [17]. Finally, continuous ambulatory PD could be used where automated PD is not available. Initially, several (10-12) exchanges per day are likely to be required, with the ability to reduce this to 4-5 exchanges per day after 3-4 days, depending on the clinical evolution.

Unpublished data from Dr. Bazarra Durand from Clínica Ricardo Palma in Peru presented during a webinar entitled "COVID-19-associated AKI treatment protocol and Latin America experiences" shows that PD can be used to treat COVID-19 patients with severe AKI. They reported using high-volume PD in three critically ill patients with low fill volumes $(20 \mathrm{~mL} /$ $\mathrm{kg}$ ) and rapid exchanges (dwell time from 35 to $60 \mathrm{~min}$ ) for $24 \mathrm{~h}$. At the time of the report, 2 of the 3 patients remained on acute PD (one having died); no mechanical or infectious complications related to PD were reported.

Since studies from Latin America have shown that patients with AKI who are treated with PD have similar rates of all-cause mortality, kidney function recovery, and infectious complications compared with patients treated with other modalities, and as clinical experience and studies increase worldwide, with early reports suggesting no differences in outcomes compared with other types of RRT, and considering the shortage of CRRT and IHD machines and supplies, PD may prove an important means of expanding access to RRT for COVID-19 patients with AKI, especially in low- and low-middle-income countries in the region.

\section{The Use of Specialized Membranes in Latin America}

Among the possible mechanisms for the development of AKI in COVID-19 is the direct damage caused by the systemic inflammatory response, in its most severe expression resulting in cytokine storm with associated hypoxia and deleterious renal effects resulting from impairment of other organs (e.g., cardio-renal, hepato-renal, pneumo-renal, neuro-renal, 
Table 3. Adsorbent membranes and cartridges in Latin America

\begin{tabular}{|c|c|c|c|}
\hline Membrane & Properties & Mechanism & Available countries \\
\hline oXiris & $\begin{array}{l}\text { Membrane AN69, covered } \\
\text { with heparin }\end{array}$ & $\begin{array}{l}\text { Absorption of endotoxines and } \\
\text { cytokines }\end{array}$ & $\begin{array}{l}\text { Mexico, Colombia, Panama, Costa Rica, } \\
\text { and Brazil }\end{array}$ \\
\hline Cytosorb & Porous polymer beads & $\begin{array}{l}\text { Absorption of endotoxines and } \\
\text { myoglobin }\end{array}$ & $\begin{array}{l}\text { Panama, Chile, and Mexico; Argentina } \\
\text { and Brazil (to start) }\end{array}$ \\
\hline Thoramixyn & $\begin{array}{l}\text { Synthetic membrane coated } \\
\text { with polymyxin B }\end{array}$ & Absorption of endotoxines & Not available \\
\hline HA330 & $\begin{array}{l}\text { Resin-directed } \\
\text { hemoadsorption }\end{array}$ & Absorption of endotoxines & Argentina, Colombia, Ecuador, and Chile \\
\hline
\end{tabular}

among others) [18]. Membranes and cartridges with specialized characteristics may have a role in treating such patients as they are able to remove pro-inflammatory IL- 6 and other cytokines. Such extracorporeal organ support therapies have previously been used in SARS, MERS, and influenza and, in some centers, remain commonly used for patients with sepsis [19]. They can be divided into blood purification with high-cutoff membranes and absorbent therapies. In the present situation, nephrologists in the region are beginning to gain experience in the use of hemoperfusion and absorption in combination with CRRT and also with extracorporeal membrane oxygenation. Emerging therapeutic options include coupled plasma filtration and adsorption, a therapy that adsorbs anti-inflammatory mediators. Coupled plasma filtration and adsorption requires a plasma filter, a resin cartridge, and a high-flux dialyzer and is available in some Latin-American countries, as shown in Table 3 [20]. In countries were these filters are available, the primary indication for use was sepsis with AKI. In the authors' experience, the presence of AKI was often critical for the decision to initiate treatment in patients with COVID-19. The two main reasons for choosing the oXiris filter were the fact that it was the only adsorbent filter available and the reduction of cytokines/endotoxins and the improvement of hemodynamic instability as shown in some case series [21].

\section{Conclusions}

AKI is a common complication of COVID-19 and is associated with increased morbidity and mortality. A high proportion of patients with COVID-19 who develop severe AKI go on to require RRT. All types of RRT are currently available in most referral centers in Latin America; unfortunately, some types of RRT like CRRT can occasionally not be provided because of the lack of materials or higher costs. In the authors' experience, in COVID-19 patients with AKI who require RRT, any form of RRT can be considered, with choice depending on experience and resources. Where resource limitations are acute, units may consider PIRRT and/or PD, given their potential advantages as outlined above. In Latin America, it is encouraging to see different therapies being adapted to fit the actual context of COVID-19 pandemic in order to meet the surging demand for RRT. Communication between centers across the region should continue and will be an important part of ensuring that best care is provided, as efficiently as possible, to all patients who require it. 


\section{Conflict of Interest Statement}

The authors have no conflicts of interest to declare.

\section{Funding Sources}

None.

\section{Author Contributions}

The authors have contributed to the writing of this paper in the following way: conceptualization: Rolando Claure-Del Granado. Writing the original draft: Rolando Claure-Del Granado, Gustavo Casas-Aparicio, Guillermo Rosa-Diez, Lilia Rizo-Topete, and Daniela Ponce. Reviewing and editing final manuscript: Rolando Claure-Del Granado, Gustavo Casas-Aparicio, Guillermo Rosa-Diez, Lilia Rizo-Topete, and Daniela Ponce.

\section{References}

1 Guan WJ, Ni ZY, Hu Y, Liang WH, Ou CQ, He JX, et al.; China Medical Treatment Expert Group for Covid-19. Clinical Characteristics of Coronavirus Disease 2019 in China. N Engl J Med. 2020 Apr;382(18):1708-20.

2 Wang D, Hu B, Hu C, Zhu F, Liu X, Zhang J, et al. Clinical Characteristics of 138 Hospitalized Patients With 2019 Novel Coronavirus-Infected Pneumonia in Wuhan, China. JAMA. 2020 Mar 17;323(11):1061-9.

3 Hirsch JS, Ng JH, Ross DW, Sharma P, Shah HH, Barnett RL, et al.; Northwell COVID-19 Research Consortium; Northwell Nephrology COVID-19 Research Consortium. Acute kidney injury in patients hospitalized with COVID-19. Kidney Int. 2020 Jul;98(1):209-18.

4 Siddiqi HK, Mehra MR. COVID-19 illness in native and immunosuppressed states: A clinical-therapeutic staging proposal. J Heart Lung Transplant. 2020 May;39(5):405-7.

5 Lombardi R, Rosa-Diez G, Ferreiro A, Greloni G, Yu L, Younes-Ibrahim M, et al.; Acute Kidney Injury Committee of the Latin American Society of Nephrology and Hypertension Working Group. Acute kidney injury in Latin America: a view on renal replacement therapy resources. Nephrol Dial Transplant. 2014 Jul;29(7):1369-76.

6 Lombardi R, Ferreiro A, Claure-Del Granado R, Burdmann EA, Rosa-Diez G, Yu L, et al.; EPILAT-ITA Study Group. EPILAT-IRA Study: A contribution to the understanding of the epidemiology of acute kidney injury in Latin America. PLoS One. 2019 Nov;14(11):e0224655.

7 Murray P, Hall J. Renal replacement therapy for acute renal failure. Am J Respir Crit Care Med. 2000 Sep;162(3 Pt 1):777-81.

8 Kellum JA, Ronco C. Dialysis: results of RENAL - what is the optimal CRRT target dose? Nat Rev Nephrol. 2010 Apr;6(4):191-2.

9 Bagshaw SM, Chakravarthi MR, Ricci Z, Tolwani A, Neri M, De Rosa S, et al.; ADQI Consensus Group. Precision Continuous Renal Replacement Therapy and Solute Control. Blood Purif. 2016;42(3):238-47.

10 Claure-Del Granado R, Mehta RL. Fluid overload in the ICU: evaluation and management. BMC Nephrol. 2016 Aug;17(1):109.

11 Rosa-Diez G, Greloni G, Crucelegui M, Bedini-Roca M, Heredia-Martínez A, Coli ML, et al. Factors determining a low dose of haemodialysis as measured by ionic dialysance in critical patients with acute kidney injury. Nefrologia. 2012 May;32(3):359-66.

12 Kielstein JT, Schiffer M, Hafer C. Back to the future: extended dialysis for treatment of acute kidney injury in the intensive care unit. J Nephrol. 2010 Sep-Oct;23(5):494-501.

13 Lombi FR. G.; Greloni, G. How do we treat acute kidney injury (AKI) with dialysis in Argentina? Results of a national survey Nefrología. Dial Transplant. 2012;32(4):198-207.

14 Edrees F, Li T, Vijayan A. Prolonged Intermittent Renal Replacement Therapy. Adv Chronic Kidney Dis. 2016 May;23(3):195-202.

15 Gabriel DP, Caramori JT, Martim LC, Barretti P, Balbi AL. High volume peritoneal dialysis vs daily hemodialysis: a randomized, controlled trial in patients with acute kidney injury. Kidney Int Suppl. 2008 Apr;73(108):S8793.

16 Ponce D, Berbel MN, Abrão JM, Goes CR, Balbi AL. A randomized clinical trial of high volume peritoneal dialysis versus extended daily hemodialysis for acute kidney injury patients. Int Urol Nephrol. 2013 Jun;45(3):869-78.

17 Almeida CP, Ponce D, de Marchi AC, Balbi AL. Effect of peritoneal dialysis on respiratory mechanics in acute kidney injury patients. Perit Dial Int. 2014 Jul-Aug;34(5):544-9.

18 Ronco C, Reis T, De Rosa S. Coronavirus Epidemic and Extracorporeal Therapies in Intensive Care: si vis pacem para bellum. Blood Purif. 2020;49(3):255-8. 
19 Ronco C, Reis T. Kidney involvement in COVID-19 and rationale for extracorporeal therapies. Nat Rev Nephrol. 2020 Jun;16(6):308-10.

20 Peerapornratana S, Manrique-Caballero CL, Gómez H, Kellum JA. Acute kidney injury from sepsis: current concepts, epidemiology, pathophysiology, prevention and treatment. Kidney Int. 2019 Nov; 96(5):1083-99.

21 Fegmin S, Zhang H, Zhu G, Yan L, Lu Y, Fang Q. The adsorbing filter Oxiris in severe COVID-19 patients: A case series. Artif Organs. 2020. https://doi.org/10.1111/aor.13786. 